\title{
Intersectional Stigma, Identity, and Culture: A Grounded Theory of Female Escort Perspectives from Brazil and Pakistan
}

\author{
Belinda Brooks-Gordon ${ }^{1 *}$ and Nasra Poli ${ }^{2}$
}

\begin{abstract}
:
Background: Intersectional experiences, socio-cultural meanings, ethnic traditions and morals compound stigma-related stress (Jackson et al., 2020; Schmitz 2019). Sex workers are subject to various stigmatizing forces which can lead to secrecy, isolation and lack of social and cultural support (Koken 2012).

Stigmatizing forces include structural humanitarian governance and aid interventions that conflate migration and sex work with insidious constraints and coercion. This study explored how migrant female sex workers from distinctive ethnic cultures manage their identity on a day to day basis in relation to the separation of work and home life.
\end{abstract}

Methods: The perspectives of female sex workers were collected via a series of in-depth semi-structured interviews. The inclusion criteria were that the women had worked in sex work for over 18 months, defined their involvement in sex work as voluntary, and were over $18 \mathrm{yrs}$ of age. The perspectives of seven women from South Asian (Pakistani), Brazilian, and British backgrounds were analyzed using Grounded Theory (Glaser and Strauss, 1967). Ethnicity was considered to explore how the women experienced stigma, how it impacted on the management of their identity, and how the process of change occurred.

Results: The women used a variety of methods to maintain work and home life boundaries, processes they used switch into a role and all experienced stigma and tried to deal with it in ways such as concealment from friends and family. Two core categories and properties emerged from the data as participants felt guilt and/or shame but only the South Asian participants spoke of this with reference to their culture and religion.

Conclusion: It was not migration per se but rather the relationship of migration to culture that was key to identity management. Participants reflected that as their country was considered collectivist country with interdependent thought, that any negativity felt could not only be reflected on the individual, but also the entire family. For these reasons Pakistani sex workers were subject to more complex stigmatizing forces, shame and guilt as regards risk and exposure. Discussion focusses on the processes and management strategies used to extend social and cultural support.

Keywords: Sex work, stigma, intersectionality, migrant, culture.

\footnotetext{
${ }^{1}$ School of Psychological Sciences, Birkbeck, University of London, London WC1E 7HX. b.brooks-gordon@bbk.ac.uk

${ }^{2}$ School of Psychological Sciences, Birkbeck, University of London, London WC1E 7HX.

* Correspondence: b.brooks-gordon@,bbk.ac.uk BB-G Tel: +44 7979006670
} 


\section{Introduction}

This paper explores the experiences of second generation migrant women sex workers and examines with a gendered lens the determinants and mechanisms to both avoid and deal with stigmatization (Valadier, 2018). Drawing on recent work on intersectional experiences, stigma-related stress, and psychological health (Jackson et al., 2020; Iram, et al. , 2019; Schmitz et al., 2019) and relationship dynamics between female sex workers and their family groups (Onyango, 2018) we aim to understand the resilience and vulnerabilities of independent escorts dealing with stigma (Koken, 2012).

It is well-documented that even at the international humanitarian level that governance can be implicated in the dynamics of stigmatization (Brooks-Gordon et al, 2020). This is but one of the levels that the social and institutional ecology of protection becomes one of sexual control. Such control inevitably becomes greater at a time of panic, disease outbreak or pandemic and it can lead to narratives of punishability that are further institutionalized at national, regional, and inter-personal level against sex workers (Shahzadi and Jalil, 2008).

Classic work on stigma focussed on public opinion and attitudes towards a person who fails to carry out the societal expectations that were set out for them, arguing stigma to be an attribute that is deeply discrediting within a particular social interaction and thus offending against 'norms of identity and being' (Goffman (1963, p37). Furthermore the person who has this attribute is 'reduced from our minds from a whole and usual person, to a tainted discounted one'(Goffman (1963, p43). Social stigma is therefore a mark of shame, a stain on one's character due to disapproval from society about an aspect of an individual's behaviour. Updating and extending Goffman's (1963) theoretical model of stigma Link and Phelan (2001) argued there were several different factors to consider when stigmatizing behaviors such as stereotyping, labeling and distancing from others occurred. These factors have been found to be due to the differential distribution of social, economic and political power (Scambler, 2007) stigma was therefore viewed as being a process and constructed through structural power.

\section{'Whore' stigma}

Pheterson (1993) constructed a more specific theory on why there is stigmatization of female sex workers (FSWs) and it was argued that stigma is felt due to FSWs committing offences against gendered norms of honour and dishonour. Seven offences were identified: having sex with strangers; having sex with multiple partners; taking sexual initiative and control and being an 'expert'; asking a fee for sex; being committed to satisfying men's lusts and fantasies; being out alone on the streets at night dressed to incite or attract men's 
desires; being in the company of supposedly drunk or abusive men whom they can either handle (as they are 'vulgar' women) or not handle (as they are 'victimized' women). The notion of the 'whore' stigma, as a stigma that aims to silence and degrade those that it targets was thus developed (Pheterson, 1998). It emphasizes their 'shameful differentness' and therefore prevents women from 'freely exploring, experiencing and naming their own sexuality for the fear of being called a whore' (Alexander, 1998). Due to the discrimination and stigmatization of sex workers they remain under-represented, over-judged and live their lives with little or no support. Research carried out on support and stigma with sex workers has focused on health-related issues with regards to the prevalence, transmission and seeking of help for HIV and sexually transmitted diseases (eg: Day and Ward, 1997; Brown at al, 2003; Duffy, 2005; Scambler and Paoli, 2008) as one of the fundamental impacts of stigma is the restricted access to health services (Bodkin et al, 2015; Rael 2015; King et al, 2013; Scorgie et al., 2013; Lazarus et al., 2012). This is an issue of growing importance in a global pandemic era.

Researchers have tried to establish how FSWs cope with the stigma they experience, and shame and guilt were some of the main emotions evoked by stigma in British studies (Church, et al, 2001; Sanders, 2005). Shame was felt when women considered the risks of doing sex work as they were aware that by going against societal and familial expectations of them they would be the recipient of social and legal disapproval. Shame was felt due to inner conflict about the societal condemnation of sex work, and even if content with the work they were still at risk of internalizing societal opinions of sex workers which could undermine the internal sense of self-worth and lead to negative impact on well-being (Bell et al, 1998). Coming to terms with this guilt they questioned individual self-worth by keeping silent to limit the impact of stigma. Other issues related that have emerged are the lack of support and isolation with lying and secrecy identified as coping mechanisms for the management of emotions and to prevent friends and family from finding out and keeping work and home separate was important and this boundary enabled them to manage their identity (Sanders, 2005).

It is not the case, however that all sex workers feel stigmatized as various studies have found that sex workers did not feel stigmatized but instead were satisfied with their job and reported no difference or higher levels of self-esteem since entering the industry compared to people not working in sex work (Prince 1986 in Kimmel and Aronson, 2004). Sloan et al (1998) found that sex workers found their job empowering and liberating thus producing positive effects. This is supported by findings that do not find any evidence that sex work is associated with mental and physical illnesses 'there were no differences in mental health... or in selfesteem...between two groups comprising female sex workers and non sex working women by Romans et al (2001). It is possible that the states that adopt a more progressive view with decriminalization or at least 
partial decriminalization of sex work may impact on stigma felt. For example, established evidence by Vanwesenbeeck (2005) showed that that indoor FSWs did not exhibit a higher level of emotional exhaustion or lower level of work-related personal competence than a comparison group of female health care workers. For some women it offers a place for self-development, financial empowerment and security, there is thus no universal sex worker experience (Wahab, 2004). This heterogeneity poses a challenge for empirical research as the nature of sex work often means that groups are vulnerable and hard to reach and/or unwilling to participate for fear of marginalisation or arrest (Spice, 2007).

\section{Individual differences}

There are therefore clearly other mediating factors involved in the sexwork/stigma phenomenon. Everyone has their own individual characteristics which play a part in how they perceive and cope with different issues in their day to day life. However, rather than acknowledging this diversity, much of the literature treats the sex worker population as a homogeneous group and subject to the same wider societal governance and social control and this risks misrepresenting the effects and impact of stigma on specific sex worker populations.

The maintenance of boundaries, so that work and home life do not collide, has been found to be a coping mechanism. The management of identity is an important aspect of sex work which comprises emotional labour (Hochschild, 1983). For some it is necessary to maintain a sense of self-identity by using various distancing techniques so that the 'real self' is kept separate from work. Some of the boundaries that have been identified are; using a different name, working in a different geographical area, avoiding intimate relationships- especially with clients, body exclusion zones, preparation routines and role playing (Brewis and Linstead 2000; Sanders, 2005). Due to the intensity and intimacy of the work, some women do not find the separation process easy and adopt these methods to maintain a separation of identity and to make their earning through the transaction of sex possible (Brewis and Linstead, 2000). It has thus been argued that sex workers create a 'manufactured identity' specifically for the workplace (Sanders, 2005). It is an emotion distancing strategy whereby when one controls their feelings and puts the clients need above their own (Hochschild, 1983). It is functional on two levels. Firstly, it is used as an emotion management strategy for protecting against any psychological harm, which may be caused due to the selling of sexual services and because of stigma and pressures from society. Secondly, it is used to create a 'prostitute role' so they are able to conform to the popular imagery of sex work and furthermore capitalize on their own sexuality (Sanders 2005). The setting up of boundaries of sex work, the perception and internalization of stigma and the overall management of identity are subject to individual differences such as gender, and age. 


\section{Cultural determinants of stigma}

From a cross cultural perspective, stigma is a shared experience, but across cultures the moral meanings, practices and outcomes of stigma differ (Yang et al, 2007) and this is due to a number of reasons. One that being cultures are rooted in their philosophical traditions which includes having different views of the self and the experience of guilt and shame. An example of this was given by Benedict (1946) who described Japanese culture as a 'shame culture' and the United States culture as 'guilt culture'. It was firstly because the United States is an individualistic country and emphasizes 'independent' concepts of the self and this reflects a view that people are separate from others and they are individuals. Secondly, Japan is a collectivistic country, it promotes 'interdependent' concepts of self. Individuals with this conception of self viewed themselves in terms of the connections they have with other people. Therefore, external influences' such as other people's thoughts and feelings play an important role in the culture (Wong and Tsai, 2007). Culture was also found to be implicated in stigma and research by Wong et al (2010) in Hong Kong focused on how FSWs as a group experienced and negotiated stigma. Their findings with 49 female sex workers were that stigmatizing forces in their daily life compelled them to conceal their identities and withdraw from their social networks. This stigma arose from their employment and various negative interactions with the public, police and their family, and manifested in ways such as physical and verbal abuse. In parts of Africa and the USA sex workers face criminalization and culture that denounces sex work on religious grounds (Koken, 2012; Scorgie et al, 2013) so that religion may also be a mediating factor.

\section{Self-governance and coping strategies}

One clear theme is the impact that internalised stigma has on psychological health. Sex worker populations working both on and off-street often take on, or own the stigma prevalent in their society and the resulting feelings of shame, guilt and self-blame (Fick, 2005) tax their coping resources, placing a significant burden on their psychological health (Kocken, 2012). Sex workers interviewed as part of an advocacy task force spoke of using pseudonyms instead of their own name when working in order to separate their identity. The majority of participants chose to conceal their occupation and spoke of the anxiety this aroused and the burden of deceiving those around them continuously. In protecting themselves from the anticipated stigma from their communities, however, the sex workers adopted a coping strategy that actually led to increased social isolation and loneliness (Fick, 2005). Koken's (2012) study of independent escorts echoed these findings with participants fearing they would be labelled for life long after they left sex work and ultimately these fears determined their decision to hide their occupation from family or friends to protect themselves from the anticipated judgement and loss of social status. This also led to increased isolation and created barriers to accessing informal social support networks and the biggest contributor to burnout was lack of a support system as one participant found that by being open with family and friends sex workers were able to 
reduce this risk and thereby gain a support system. Concealment was found to extend to intimate relationships and women in the study by Bellhouse et al., (2015) of women doing indoor work in Australia, women cited the stigma associated with their job as a key factor causing negative issues in their relationship. Of the women in relationships, half had chosen not to disclose their job to their partner which led to feelings of guilt over the dissemblance.

\section{Socio-tolerance vs restrictivism}

In Latin American culture, for example in Brazil, sex and sexuality are embedded and more openly part of the culture (Parker, 2009). In addition there is less tolerance of state repression, there is much conversation about health and female sexual desire. Governance structures contain no laws forbidding adult sex work, indeed Ordinance 397 recognised sex work as an 'official' occupation with those registered as 'sex professionals' taxed as autonomous workers and entitled to regular employment benefits including maternity pay, a state pension fund and medical care (De Lisio, 2017). While this increased social tolerance was tested in the moral panics in the lead up to the FIFA World Cup in 2014 and the Rio Olympic Games in 2016 tolerance remains part of the fabric of Brazilian culture despite perceptions of stigma more broadly in Latino/a culture (Rael, 2015). Governance is also underpinned by a strong sex worker movement in the Brazilian Network of Prostitutes (BNP) who promote sex worker support and a strong collective identity for sex workers. Working with the Brazilian Ministry of Health, the BNP became instrumental in the creation of internationally applauded strategies to prevent the spread of HIV and AIDS (De Lisio, 2017).

Pakistan by comparison is a collectivist country and an Islamic state where restrictions are placed on the practicing of sex, and Pakistan is known to have large populations of female sex workers (FSWs) with considerable geographic heterogeneity in their characteristics. geographic and network mapping data collected among FSWs in 15 cities across Pakistan in 2011 as part of the Canada-Pakistan HIV/AIDS Surveillance Project. Fify five percent of the estimated number of FSWs are concentrated in Karachi and Lahore, and these include establishment-based and non-establishment-based sex workers operating through brothels, homes, kothikhanas, streets and by cellphone. The work by Emmanual et al, (2013) on the organisation, operational dynamics and structure shows Pakistan to have a long history of sex work, although illegal and taboo it is an 'open secret' within the society. The dynamics are also fast changing and traditional big brothels are dwindling and small brothels called kothikhanas are disappearing. The majority of the FSWs now operate from homes (52\%), while the dwindling number of street-based sex workers work from small hotels. Thus, the obvious routes of discrimination and marginalization are disappearing. While discrimination becomes less for home-based workers. Identification of these FSWs for any preventive measure against HIV has become increasingly difficult particularly because of prevalent illiteracy, thus 
increasing their vulnerability to HIV infection and STIs. Behavioural insights into female sex workers in Lahore (Shahzadi and Jalil, 2008).

Across the United Kingdom, an individualistic western society with liberal, tolerant, and open attitudes to sex and sexuality (evidenced from statutory support for same sex marriage and LGBT rights) it can argued that the quasi-criminalized status of sex work has led to the social stigma around sex work, which it can be argued may due to an underlying sexual conservatism and lack of sexual expression open to women (Spector, 2006). Sex work in Britain is only semi-tolerated due to the stigmatized nature of work and quasicriminalized context (Brooks-Gordon, 2006). The stigmatized nature of the work for female sex workers emanates, in part, from societal normative forms of gender identity for women. Sex workers of course no longer just reside on the streets or in brothels; they are escorts, pole dancers, and adult erotic film performers working from a variety of rented premises or working from home.

Despite the work on individual cultural groups there has been very little research done to examine crosscultural similarities, differences and coping mechanisms of FSWs working as escorts, especially in light of the factor that stigma is affected by differing cultural meanings and practices. In the study presented we will try to identify how second generation escorts from different ethnic backgrounds in the United Kingdom experience stigma and juggle their work and home life. Our aim is for women of Brazilian, Pakistani and English cultural backgrounds to give an account of their working and personal life grounded in their experience of socio-cultural governance and stigmatization to explore how these women balance work and home life and what governmental impact ethnic background has on the management of stigma and their individual identities.

\section{Methodology}

\section{Design and Recruitment}

Recruitment was carried out through a snowball sampling of women attached to one of two agencies in central London. Initial contact was made through the agencies and any contact made thereafter was done directly with the women via email or mobile phone. Participant were co-researchers throughout the process and helped guide subsequent information sheet, interview schedule, and the extrapolation and interpretation of data. In depth, semi-structured interviews were conducted with seven women who self-defined as working escorts.

Participant selection was based on three criteria: they were over 18 years of age, had worked as an escort for a minimum of 18 months, and defined their involvement in sex work as voluntary. All participants were 
either of Brazilian, South Asian, or English descent and comprised two Brazilian participants, three Pakistani participants, and two English women. Each was given an information sheet and briefing before a scheduled interview was due to take place. The guiding methodological approach for the study was Glaser and Strauss's (1967) grounded theory so that the emerging theories were grounded in participants' perceptions and experiences.

\section{Ethics}

Ethical approval for the study was granted by the Departmental Ethics Committee. Participants were told all about the study so that consent could be full and informed. Participants were told they did not have to answer any questions they didn't want to and that the interview could be stopped at any time. All information was anonymised to so that they were not recognisable and interview tapes and data were be kept locked and only accessible by the authors. Participants were free to withdraw from the study at any stage. All participants were given information about different organisations that provide help and support to sex workers. (Birkbeck School of Psychological Sciences Ethics Committee, approved code: 101126)

\section{Data Collection}

An interview schedule was prepared with a list of relevant topics and questions for exploration. Participants were told that they could have the interview questions can be shown to them in advance to put them at ease about the content of the interview but none chose this option. Interviews were conducted in the women's workplace or home. All interviews were conducted in English and lasted between 40 and 75 minutes. Apart from one interruption in one interview nothing differed in the process of the different interviews. All interviews were taped using a digital voice recorder and were transcribed verbatim. To maintain confidentiality, neither women's real names nor work names are used but pseudonyms were applied to preserve anonymity. The core demographic characteristics of participants are outlined in Figure 1.

Figure 1: Demographics of interview sample

\begin{tabular}{|lccccc|}
\hline NAME & AGE & ETHINICTY & $\begin{array}{l}\text { RELATIONSHIP } \\
\text { STATUS }\end{array}$ & CHILDREN & TIME WORKING \\
\hline Anna & 27 & Brazilian & Single & None & 3 years \\
\hline
\end{tabular}




\begin{tabular}{|lcllll|}
\hline Tanya & 36 & Mixed Brazilian & Married & One (aged 12) & 6 years \\
Cara & 24 & Asian Pakistani & Single & None & 2 years \\
Maria & 26 & Asian Pakistani & Single & One (aged 4) & 8 years \\
Priya & 23 & Asian Pakistani & Single & None & 2 years \\
Linda & 37 & White English & Single & None & 14 years \\
Sophie & 28 & White English & Single & None & 10 years \\
& & & & & \\
\hline
\end{tabular}

Data was analysed using the Grounded Theory approach of Glaser and Strauss (1967). Once all interviews were completed, transcripts were written up and data managed using Scribe transcription software to maintain the authenticity of the women's voices. The data was axial coded line by line by the second author until data saturation occurred and no new categories emerged, the data was re-examined by the first author.

\section{Reflextivity}

This study emerged after a friend of the second author disclosed that she was a working as an escort. Both women are South Asian, and the friend is of Pakistani descent. She was afraid that her parents and family would find out and fearful of what the implications of this exposure might be. From a cultural standpoint it was possible to understand fully where her fears came from and know that her family wouldn't take it well including the high probability that her family would 'cut all ties' with her. From this emerged the central research question as to how escorts manage their lives, especially those from different cultures and ethnicities, how they manage it, and deal with any negativity directed at them, and how the larger structural governance is mediated at the micro-level in the governance of daily life and work. The Brazilian and English participants in the study took more time to relate their experiences, it was more of a fully informed conversation about their working and personal life. The Brazilians were more open, comfortable and confident enough in their lack of stigma to relate that they found aspects of the work enjoyable. The English participants said less. The Pakistani participants were much directed, orientated towards family values and the shame culture. It was assumed that this was because they felt that the interviewer already knew what they 
are talking about and this shared cultural understanding made the whole process more facilitatory than it might have been had there not been a shared cultural heritage.

\section{Results}

The women described a variety of methods of how as an escort they juggle their day to day life, especially with regards to work and home life. All participants spoke of stigma and ethnicity, and how it affects them and the overall management of their identity. The nuances between women of different ethnicities was thus explored to understand different degrees of stigma and how this impacted on the management of identity.

Figure 2 : Management of Identity

\begin{tabular}{|c|c|}
\hline \multicolumn{2}{|c|}{$\begin{array}{c}\text { Core Experience of Management of Identity: } \\
\text { Living a double life. }\end{array}$} \\
\hline Category & Properties \\
\hline Concealment of identity & “...work with a different name" \\
Different Persona & "It's not me, it's a persona" \\
Process of Change & "You need time to switch like \\
& putting your make-up on" \\
\hline
\end{tabular}

Two different categories emerged: Management of Identity (MOI) and Impact of Stigma (IOS). Each had several properties. Table 1 and 2 depicts the two categories and their properties. The Properties are discussed below.

\section{Management of Identity}

\section{Concealment of identity}


All the women reported on how they have had to conceal their identities so that friends and family don't find out about their work. This included using a different name and age whilst working and having separate phones; one for work, one for home to keep their identities separate. They also did this to protect themselves so that clients did not get the 'real self'. All spoke of having to lie and dissemble to cover up the truth about their whereabouts and what they were doing. One spoke of how her ethnicity dictated what information she gave and her geographical location of work in case family and friends saw her.

"I have two different phones, one for work, one for home. I also use a different name. I usually tell them I'm not Pakistani, that I'm mixed, that way if there's any Asian clients they don't ask me too many questions. Asian people are really nosey; they ask you where you are from, what village, who are your parents etc. Although, I like to think clients won't ask that! But, you never know. Also, just in case someone recognises my pictures, it helps to say I'm mixed and have a different name." (Cara, 4.31). "well you have separate phones obviously. They only know one number ...it's difficult” (Sophie, 14.1) "Well lying is one of them. Also I keep my numbers separate.”(Linda, 6.8)

"I use a different name because I don't want anyone I know recognising me. And if I put down an Asian name then I think a lot of Asian guys will want me, which puts me off. I don't want them sticking their nose in my business...working away...Because I don't want them to see me” (Maria, 4.17)

Concealment and lying was a key factor in facilitating the management of these womens' identities in order to keep their work identity and home identity separate. It is done to avoid ostracisation from family and friends so they are able to do their job as they wish. Previous studies have found similar results (Campbell, 2000; Sanders, 2005). Interestingly with the Pakistani women, there are a lot of references to Asian men and the avoidance of them. This was a reflection upon their cultural norm as they are from Muslim families; sex before marriage and unnecessary contact with the opposite sex is forbidden. It is speculated that they believed Asian men, particularly Pakistani, would reveal the women's true identity to others, as they were going against their religious and cultural norms. The two English participants, however, selectively chose to disclose information to a number of close friends, and the Brazilian women both chose to tell close kin relatives. In one case, her mother as the mother is looking after her daughter. In the other case, it was her sister. This reflected close relationships within their kin groupings, but she didn't reflect openness to wider groups of people knowing.

\section{Different Persona}

The women all spoke of having a different persona; one for work, one for home. At home they see themselves as ordinary people; when they are about to work they feel they 'switch' into a different role, as if 
it wasn't them and they were a completely different person. This is because they felt their family and friends would not be supportive of what they are doing.

"Well, I... by the time I leave home I'm a different person, it's not me, I'm this persona. I've found that by doing this, mentally I'm well prepared. In the beginning I used to feel really shit about it, especially when I thought of my family and if they found out. But now by becoming this persona I can rationalise it better. It's just a job. (Cara, 5.3)

“...when you work under a different person, you become a different person, its not you, it's a different identity" (Sophie, 12.22).

\section{The Change Process}

The women spoke of a process of change, a routine of getting them ready to get into their 'role' or 'persona' of a sex worker before going to see a client. This enabled them to manage their emotions effectively by rationalising the whole their intentions and switching off emotions that may get in the way of doing their job. The process, although described as difficult, included getting their hair and make-up done and wearing clothing that they possibly may not wear when they are not working.

"Sometimes it can be very difficult. Its like if you are having a normal day and do things you normally do, like for me I go to the shops and then I go and see a client. It's very hard. You NEED the TIME to SWITCH. Like putting your make-up on, having a wash HELPS, Putting sexy clothes on as well, it is very difficult to see a client if you are in your normal clothes" (Anna, 12.2)

"It can be difficult, like I have a horse in the stable and if I'm going there after seeing a client people see I have loads and loads of make-up on, so sometimes what I try and do is wear lots of make-up anyway so they think its normal for me. But yea that can be very difficult" (Sophie, 7.12)

"I want the money and I want to be good at what I do. But that's it. It's an act. Emotionally I'm completely switched off about it." (Linda, 9.3)

\section{Impact of Stigma}

\section{Lack of Disclosure}

The impact of stigma was found to be an important issue with all of the women as they feared that, in other people's perceptions, they would compared to the stereotypical image of a sex worker, that it was unrepresentative of who they are, thus they would be judged negatively. This can be seen in Figure 3.

Figure 3: Impact of Stigma 


\section{Core Experience of Impact of Stigma:}

\section{Loneliness}

\begin{tabular}{|c|c|}
\hline Category & Properties \\
\hline Lack of Disclosure & "I say I'm a babysitter outside \\
London" & $\begin{array}{c}\text { "this is the negative side, it make me } \\
\text { feel like guilt, make me feel dirt" }\end{array}$ \\
\hline Shame and Guilt & \\
\hline
\end{tabular}

The women therefore chose not to tell anyone about what they were doing as they believed there would be a lack of support.

"I don't know about you but to me the stereotype of the image of the sex worker, prostitute is fat middle aged woman, bleached hair, skin tight clothing, on street corner, being you know sort of, just that WHOLE image, that whole stereotype of being seedy and dirty, you know sort of drug addicts, just sort of doing it for their crack money. Where as the reality of it is so, so different." (Linda, 7.16) "[On other peoples view]...As whores, money grabbing whores or maybe they think they are on drugs. It's not the case, some girls do drugs but majority don't. I think the majority are young intelligent women who you wouldn't dream was an escort." (Sophie, 14.6)

Interestingly one woman spoke of her own antipathy towards sex workers before she had entered the industry, thus revealing a priori knowledge of stigma. She spoke of how she found it 'terrible' and did not want any sort of relationship with these girls. But then when she started escorting, her opinions changed, and she realised that everyone has a reason for doing it and that everyone is not the same.

“...I was one very terrible with girls in Brazil because always I was working as secretary in Brazil. And when I saw some girls working as pros I say oh this is disgusting. If you can find some offices, go clean, go clean some gardens, go do something but don't sell your body, this is disgusting, this is terrible. But when are you come into the business, you start to understand everything have a reason. They are not less or more than you, they just have some reason you know." (Anna, 7. 17) 
For these reasons all the women chose not disclose that they were working, instead choosing concealment. They are leading a double life to avoid rejection and anger. This enabled them to maintain a good level of self-esteem as they believed their friends and family would not be happy or supportive of what they were doing and they wouldn't want to know them anymore. Although all the participants spoke of their worries of the effects of disclosure to friends and family, it was the Pakistani participants who only referred to their religion and culture when speaking about it. The other women spoke of the risks of exposure and what others may think of them but only the Pakistani participants spoke of disclosure, risk, culture and religion in the same context. This is an example of how cultural and moral standings can dictate what people think and behave.

"Because within our culture and religion prostitution is wrong, it's immoral, it's a massive sin. Like I said before, you don't have sex before you are married... and then to go and sleep with loads of guys for money! It's not right, and... if my family and relatives found out it would just bring shame to the family, they would not be able to face these people again, knowing that all these people know that their daughter is a prostitute." (Cara, 2.33)

"It goes against our religion, our culture isn't it. It's wrong. And people gossip a lot. Once they found out about me I was in for it, my family were in for it...My mother was constantly reminding me how much I shame I had bought to the family." (Priya, 3.12)

\section{Shame and guilt}

All the women referred to shame and guilt at some point. Most felt shame because of the stereotypes and stigma surrounding sex work, and guilt because despite these stereotypes they were still doing their job and because they had to lie to friends and families about what they were doing. Because of this most felt they had no-one to talk to, no support and felt very isolated and lonely. Some felt the only people they could speak to was other working girls, because they understood where they were coming from.

"The only girls or people I can speak to is the working girls... But for me to talk to a friend over a pint or a coffee, I don't have it... which is quite hard." (Linda, 13.10)

"My family don't talk to me... and don't really have any friends. The only people I can talk to is some of the other girls I come across, but that's very rare" (Maria, 5.24)

One of the Brazilian participants spoke of her how she would feel if her daughter found out. She believed that her daughter would not be ashamed of her and would understand why she is doing this, once she is old enough, but as she is young now, she would be more susceptible to the influences of society, and she would be ashamed of her. 
"To be honest with you, if my daughter found out in the future...it's in the future, she will be old enough to understand. As a children now...it's...complicated Because for the society, you know...my mum is like a prostitute, it's the word we call in Brazil. Looks like you are dirty, you are not a respectable person, and you are not nice. It's the way people see in Brazil for them who start to do the job." (Tanya, 7.9)

The participants of Pakistani heritage, however, spoke of shame and guilt with reference to their culture and religion. One woman spoke of how she had been disowned by her family because of her occupation and their perception that had brought shame, not just to herself, but to the whole family. This is because she wasn't fulfilling her cultural role which is to be at home, be a wife and a mother, and only have sex with a husband. Because of this shame her family had kept her son away from her, asserting that she is 'tainted' and therefore not a good role model for him. She also spoke of how the shame could possible affect her son, and their relationship in the future, how others may put him against her.

"I don't want him to think any different of me, I'm still his mum" (Maria, 5.14)

The other woman spoke of the impact it would have on the rest of her siblings, should anyone find out. “... I don't think I could face them again. It would put so much on shame on them...I couldn't live with them in the same house knowing they know I have sex with men...Also there's marriage, nobody will want to marry me if I want an arranged marriage. And then my sisters, it may affect them too. If they have a marriage proposal and the family find out that the girl's sister is a prostitute, they will lose interest for sure. It's about honour... reputation." (Priya, 3.20)

\section{Discussion}

The aim of this study was to see how escorts from different ethnicities, working in the UK, manage their identity in terms of balancing work and home life and what sort of impact the stigma of sex work has on them. This was done via an in-depth semi-structured interviews; the findings and emerging theory grounded in their experiences.

Two dominant categories emerged from the data. The first category was the Management of Identity and this consisted of three main properties which were: concealment of identity; different persona; and process of change. These illustrate how the women were able to conceal their identity so that family and friends did not find out what their work was. This was done using various forms of concealment such as using different names and phone numbers. Another property of managing identity was to use a different persona when working: 'the escort' rather than 'the self'. This persona helped them maintain their boundaries of whom they are and where work stopped and home began. This, included in the case, of the Pakistani women, adopting a very different cultural heritage for work to avoid clients of South Asian, and particularly Pakistani origin, so that they would not probed too deeply about their background, or risk having contacts in common 
with any clients. The third property was process of change illustrating how workers transformed to became 'the escort' in an almost ritualistic process, changing hair and make-up, wearing different clothes to get mentally prepared and psyched up before going to see a client. This was what enabled them to switch their identity to 'the escort'. These findings support literature on manufactured identity and making a distinction between work and home life (Sanders, 2005; Brewis and Linstead). What is new however, is the revelation of the process of change by all the women, and the intercultural narratives of 'different persona' and the narratives of avoidance and punishability by the South Asian women.

The second category that emerged was the impact of stigma. This category had two properties which were 'lack of disclosure' and, 'shame and guilt'. All the women chose to disclose information to a select number of people and they all felt stigma and shame about different aspects of their job. This is consistent with previous literature linking stigma and shame (Bell et al, 1998; Barton, 2002; Wong at al 2010). The Brazilian participants were the only ones who told close kin such as mothers and sisters. These kin relatives were supportive, which may reflect differential attitudes about sex work and illuminate how about structural governance at legislative level is implicated in personal relationships and stigma. These women were more relaxed about their work and stated that they were able to enjoys some aspects of the work. This appears to be a reflection on the cultural norms and attitudes to female sexuality. Their ability to speak freely with close allies and kin relatives without fear of reprisals would release them from the constant nervous tension and anxiety that the fear of being found out brings. Brazilian culture is open about sexuality (Parker, 2009) hence why they were more comfortable about their work. But they still chose not to tell brothers and some friends about it in the belief they would be judgemental, so this points to a more complex gendered and intersectional dimension to stigma (Jackson et al, 2020; Schmitz et al., 2019).

The English participants chose not to disclose to anyone at all, mainly because they felt they would be judged in a negative way. On a continuum of disclosure, however, the Pakistani participants, however, fared the worst and spoke about shame and guilt in context of culture and religion and being found out. The Pakistani participants' differential interpretation and internalization as to the meaning, practices, and outcomes of stigma was accorded by their culture. This is supports the findings of Yang et al., (2007) and takes forward the findings Shahzadi and Jalil (2008) and Iram (2019) on sex workers in Pakistani culture. Participants spoke of reputation and how it impacts the whole family for in a culture with a custom of arranged and semi-arranged marriages if they wished to have an arranged marriage in the future it was believed that being found to be working as an escort would mean that other families would not want them. The same would apply to their sisters, as they would suffer stigma by association. This research therefore illustrates the notion of interdependent concepts - one person's actions affects everyone else, therefore any 
shame or guilt that is felt, is done so it accounts for not just oneself, but family members too. External influences such as these cause Asian FSWs, in this instance women of Pakistan heritage, to feel more shame and guilt about their work in comparison to English and Brazilian FSWs.

There were no large differences in the way they manage the women managed their identity, but when it came to the feeling, effect and impact of shame, the Pakistani participants felt these to a higher degree and extent. They attributed this to their culture and religion, culture because they were made to feel responsible for the whole family. Religion plays a significant part in Pakistani culture and given the prevalence of reported honour killings due to 'izzat' or lack of honour (Wasti, 2010; Al Jazeera, 2020), although reduced since Imran Khan's Tehreek-e-Insaf party took power in August 2018, is an indication of what women have faced historically (Human Rights Watch, 2018). Such findings are consistent with studies that have found a link between religion and stigma eg Wong at al., (2010) who found that sex workers attributed stigma felt to the prevailing Catholicism in their country and so chose to hide what they were doing. Both Catholicism and Islam have a taboo on sex before marriage and uphold chastity as a virtue and the women, thus felt it was too much of a risk to expose them as they would be stigmatized and not just by family and friends but also healthcare providers and doctors.

There has been very little research done on the impact of stigma on Pakistani women, especially under the constraints of culture and religion and this study provides new insights into the impact of stigma and equally highlights the complexities inherent in the field of intersectional sex worker research. The ideographic and phenomenological nature of the analysis enables us to obtain a deeper, more holistic understanding of how perceived stigma affects the psychological health and lived experiences of workers. Sex work research is fraught with limitations such as a vulnerable heterogeneous population that can be difficult to reach. Despite this the study has provided valuable insights into the differential impacts and management of this stigma on migrant sex work populations. The research shows that enacted stigma and its internalization has a fundamental impact on migrant sex worker populations of South Asian origin themselves. The resulting barriers to accessing informal social support, and fear of being exposed places a significant burden on the psychological health of FSW. The impact of stigma is clearly of concern and highlights the vulnerability of the wider sex work population. Consequently, sex work researchers have a moral obligation to overcome the inherent challenges in the field. By adopting ethical methodologies that work with rather than against the limitations and extending research beyond sex worker populations to unpick and provide a holistic view of stigma, researchers can unpick the concept rigorously in future. Such researchers will be better placed to target and influence policy makers to reform policy and practice and thus reduce psychological and physical risks to this vulnerable population. 
Although all of the participants had certain things in common (i.e management of identity and emotions felt) their personalities were different and this also impacted on how they spoke about their feelings and what was felt in the first place. Future research might expand the cross-cultural theme by looking at intersectional stigma with regard to personality traits and individual differences, cultural heritage, and migration to explore within-cultural nuance and divergence. Future research should also extend beyond the sex worker population as research is only just beginning to show, in the natural experiment that is the Covid-19 pandemic, the role of forced (physical) isolation on mental health (Logie and Turan, 2020). This would enable the role of physical isolation per se, ie the governance structures in quasi-criminalized regimes to be unravelled from psychological isolationism, loneliness, and stress caused by concealment. This is fundamental to gain a rounded perspective on sex work. Secondly, research should consider that the impact of stigma may not affect all sex workers negatively and seek to identify strengths and resilience amongst the population (eg as in Onyango, 2018; Burnes et al, 2012) and indeed the factors that provide resilience such as having at least one ally to whom workers can be their authentic self or truly supportive governance structures that support individual, human, and employment rights (c.f. Brooks-Gordon, 2018).

\section{Conclusion}

The aim of this research was explore how migrant women of differing intercultural Brazilian, Pakistani, or English heritage working as escorts in the UK balance their sex work identity and home identity with regard to role of stigma, and how stigma affects them and how they deal with it. Our findings suggest that the women have similar scripts and mechanisms by which they manage their identity to separate their work and home life. But while they all use the similar mechanisms the Pakistani women are more likely to feel shame and guilt due to the stigmatization felt by the impact of their culture than their Brazilian or English counterparts. These are, to some extent, governed by wider socio-cultural governmental factors that are determined by the moral and cultural aspects of their culture. Pakistan is a collectivist country with interdependent concepts of self, and this has an impact on how the women view themselves in a wider familial context, in this case, with regard to what impact stigma of sex workers has on women and how much guilt and shame they feel. Reinforced by criminalization of sex work and gendered societal constraints that delegitimize the work, stigma associated with sex work permeates sex workers' psyches.

\section{References}

Alexander, P. (1998) Prostitution: Still a difficult issue for feminists. In Delacoste, F and Alexander, P. (Eds.) Sex work: Writings by women in the sex industry. San Francisco: Cleis Press.

Al Jazeera, (2020) Pakistan: Three arrested over 'honour killing; of teenage sisters. 18 May 2020 
https://www.aljazeera.com/news/2020/05/pakistan-arrested-honour-killing-teenage-sisters200518181025193.html

Bell, H., Sloan, L. and Strickling, C. (1998) Exploiter or Exploited: Topless Dancers Reflect on Their Experiences. Affilia, 13.

Bellhouse, C., Crebbin, S., Fairley, C. K., and Bilardi, J. E. (2015) The impact of sex work on women's personal romantic relationships and the mental separation between their work and their personal lives: A mixed methods study. Plos ONE, 10 (10).

Benedict, R. (1946) The chrysanthemum and the sword. Boston: Houghton Mifflin.

Brewis, J. and S, A, Linstead. (2000) "The worst thing is the screwing" Consumption and the management of identity in sex work. Gender, Work and Organization, 7, 2, 84-97.

Bodkin, C. and Shaver, F. M. (2015) Reducing stigma in healthcare and law enforcement: A novel approach to service provision for street level sex workers. International Journal for Equity in Health. 14 (1) 1-7. Brooks-Gordon, B. (2006). The price of sex: prostitution, policy, and society. Willan, Cullompton Devon. Brooks-Gordon, B. M. (2018) 'Into the Light: A model of justice for workers' rights in the shadow and 'gig' economy'. In Realising Justice for Sex Workers (the Work). Edited by Sharron A. FitzGerald and Kathryn McGarry. London. Rowman and Littlefield. ISBN 9781786603944.

Brooks-Gordon, Belinda., Wijers, Marjan., and Jobe, Alison. (2020) Justice and civil liberties on sex work in Contemporary International Human Rights Law. Social Sciences 9 (1), p. 4. ISSN 2076-0760.

Brown, L., Macintyre, K. and Trujillo, L. (2003) Interventions to Reduce HIV/AIDS Stigma: What Have We Learned, AIDS Education and Prevention, 15, 1.

Church, S., Henderson, M., Barnard, M. and Hart, G (2001) Violence by clients towards female prostitutes in different work settings: questionnaire survey. American Journal of Public Health, 87, 66-70.

Cusick, L., Kinnel, H., Brooks-Gordon, B. and Campbell, R. (2009) Wild guesses and conflated meanings: Estimating the size of the sex worker population in Britain. Journal of Critical Social Policy, 29, 4, 703-719. Day, S., and Ward, H. (1997) Sex workers and the control of sexually transmitted disease. Genitourin Med, 73, $161-168$.

De Lisio, A. (2017) How Brazil's sex workers have been organised and politically effective for 30 years. The Conversation, December https://theconversation.com/how-brazils-sex-workers-have-been-organised-andpolitically-effective-for-30-years-88903

Duffy, L. (2005) Suffering, shame, and silence: The stigma of HIV/AIDS. Journal of the Association of Nurses in AIDS Care, 16, 1, 13-20.

Emmanual, F., Thompson, L. H., Athar, U., Salim, M., Sonia A., Akhtar, N., and Felstead, J. (2013) The Organisation, operational dynamics and structure of female sex work in Pakistan. Sexually Transmitted Infections, 89 (Suppl 2); ii29-ii33. doi: 10.1136/sextrans-2013-051062

Fick, N. (2005). Coping with stigma, discrimination and violence: Sex workers talk about their experiences. Cape Town. SWEAT.

Glaser, B. and Strauss, A. (1967) The Discovery of Grounded Theory. Strategies for qualitative research. Mill Valley: CA. Sociology Press.

Goffman, I. (1963) Stigma: Notes on the management of spoiled identity. Englewood Cliffs, NJ: Prentice Hall.

Hochschild, A, R. (1983) The Managed Heart: Commercialization of Human Feeling. Berkeley, CA:

University of California Press.

Human Rights Watch (2018) https://www.hrw.org/world-report/2019/country-chapters/pakistan

Iram, T., Ilyas, M., Bilal, R. A., and Parveen, S. (2019) Socioeconomic acceptability of prostitutes in

Pakistan: a diversion from prostitution. Cogent Social Sciences, 5, Issue 1.

Jackson, S. D., Mohr, J. J., Sarno, E. L., Kindahl, A. M., \& Jones, I. L. (2020). Intersectional experiences, stigma-related stress, and psychological health among Black LGBQ individuals. Journal of Consulting and Clinical Psychology, 88(5), 416-428.

https://doi.org/10.1037/ccp0000489

Jeffrey, L, A, and MacDonald, G. (2006). Sex workers in the Maritimes talk back. Vancouver: UBC Press. 
Kimmel, A, and Aaronson, A. (2003) Men \& Masculinities: A Social, Cultural, and Historical Encyclopedia. ABC-CLIO.

King, E. J., Maman, S., Bowling, J. M., Moracco, K. E., Dudina, V. (2013) The influence of stigma and discrimination on sex workers access to HIV services in St Petersburg, Russia. AIDS Behav,. Oct;17(8): 2597-603. doi: 10.1007/s10461-013-0447-7.

Koken, J. (2012) Independent female escort strategies for coping with sex work related stigma. Sexuality \& Culture, 16 (3), 209-229.

Lazarus, L., Deering, K. N., Rose Nabess, Kate Gibson, Mark Tyndall and Kate Shannon (2012)

Occupational stigma as a primary barrier to health care for street-based sex workers in Canada. Cult Health Sex. 2012; 14(2): 139-150._Published online 2011 Nov 15. doi: 10.1080/13691058.2011.628411

Link, B, G. and Phelan, J, C. (2001) Conceptualizing stigma, Annual Review of Sociology, 27, 363-385.

Logie, C.H., and Turan, J.M. (2020). How do we balance tensions between COVID-19 public health responses and stigma mitigation? Learning from HIV research. AIDS Behav 24, 2003-2006.

https://doi.org/10.1007/s10461-020-02856-8

Onyango, M. A., Adu-Sarkodie, Y., Odotei Adjei, R., Agyarko-Poku, T., Kopelman, C. H., Green, K., Wambugu, S., Clement, N. F., Wondergem, P., and Beard, J. (2018) Love, power, resilience and vulnerability: relationship dynamics between female sex workers in Ghana and their intimate partners. Culture, Health \& Sexuality, DOI:10.1080/13691058.2018.1446550

Parker, R, G. (2009) Bodies, pleasures, and passions: sexual culture in contemporary Brazil. Vanderbilt University Press.

Pheterson, G. (1993) The Whore Stigma: Female Dishonor and Male Unworthiness. Social Text: A Special Section. Edition Edited by Anne McClintock Explores the Sex Trade, 37.

Pheterson, G. (1998) The social consequences of unchastity. In Delacoste, F and Alexander, P. (Eds.) Sex work: Writings by women in the sex industry. San Francisco: Cleis Press.

Rael, C. (2015) Perceptions of sex work-related stigma in female sex workers from the Dominican Republic: Implications for HIV interventions. Sexuality \& Culture, 19(4), 674-684.

Sanders, T. (2005) Sex work: a risky business. Willan. Cullompton.

Scambler, G. (2007) Sex work stigma: Opportunist migrants in London, Sociology, 41, 6.

Scambler, G. and Paoli, F. (2008) Health work, female sex workers and HIV/AIDS: Global and local dimensions of stigma and deviance as barriers to effective interventions. Social Science \& Medicine, 66, 8, 1848-1862.

Fiona Scorgie, Daisy Nakat, Eric Harper, Marlise Richter, Sian Maseko, Prince Nare, Jeny Smit, and Matthew Chersick (2013) 'We are despised in the hospitals': sex workers' experiences of accessing health care in four African countries. Health Sex. 2013;15(4):450-65. doi: 10.1080/13691058.2012.763187.Epub 2013 Feb 18.

Shahzadi, I. and Jalil, F. (2008) Behavioural change in female sex workers in Lahore, Pakistan in HIV/AIDS prevention. Suppl 1, E163, Dec 01. International Journal of Infectious Diseases.

https://doi.org/10.1016/j.ijid.2008.05.406

Schmitz, R. M., Robinson, B. A., Tabler, J., Welch, B., and Rafaqut, S. (2019) LGBTQ+ Latino/a young people's interpretations of stigma and mental health: An intersectional minority stress perspective. Society and Mental Health, May 8, https://doi.org/10.1177/2156869319847248

Spector, J. (2006) Prostitution and Pornography: philosophical debate about the sex industry. Stanford University Press.

Romans, S. E., Potter, K., Martin, J. and Herbison, P. (2001) The mental and physical health of female sex workers: a comparative study. Australian and New Zealand Journal of Psychiatry, 35, 75-80.

Valadier, C. (2018) Migration and Sex Work through a gender perspective. Contexto Internacional, vol.40 no.3 Rio de Janeiro Sept./Dec. 2018.

https://www.scielo.br/scielo.php?script=sci arttext\&pid=S0102-85292018000300501

Vanwesenbeeck, I. (2005) Burnout among female indoor sex workers. Archives of Sexual Behaviour, 34, 6, 627- 639 . 
Wahab, S. (2004) Tricks of the trade: what social workers can learn about female sex workers through dialogue. Qualitative Social Work, 3, 2 139-160.

Wasti, T., H. (2010) The law on Honour Killing: A British innovation in the criminal law of the Indian subcontinent and its subsequent metamorphosis under Pakistan penal code. South Asian Studies. A Research Journal of South Asian Studies, 25, 2, 361- 410.

Wong, Y., and Tsai, J.L. (2007) Cultural models of shame and guilt. Chapter in Tracy, J., Robins, R. and Tangney, J. (Eds.) Handbook of Self-Conscious Emotions, 210-223. New York: Guilford Press.

William Wong, Eleanor Holroyd, Amie Bingham (2011) Stigma from the perspective of female sex workers in Hong Kong. Sociology of Health and Illness, 33, issue 1. https://doi.org/10.1111/j.14679566.2010.01276.x

Yang, L.H., Kleinman, A., Link, B.G., Phelan, J.C., Lee, S. and Good, B. (2007) Culture and stigma: Adding moral experience to stigma theory. Social Science and Medicine, 64, 7, 1524-1535. 